\section{National Black HIV/AIDS Awareness Day - February 7, 2019}

National Black HIV/AIDS Awareness Day is observed each year on February 7 to highlight the continuing disproportionate impact of human immunodeficiency virus (HIV) infection and acquired immunodeficiency syndrome (AIDS) on the U.S. black/African American (black) population.

In 2017, blacks represented $13 \%$ of the U.S. population (1), but accounted for $44 \%$ of all new HIV diagnoses (2). Among racial/ethnic groups, the highest rate of new HIV diagnoses occurred among blacks (41.1 per 100,000 population). Blacks also had the highest rate of new diagnoses of HIV infection in each of the four census regions of the United States; the highest overall rate was among blacks in the South (44.8 per 100,000 population).

Partner services is an effective, high-yield strategy for identifying undiagnosed HIV infections and thereby linking persons with newly diagnosed HIV infection into HIV care. A study reported in this issue of $M M W R$ presents the first national level analysis of HIV partner services offered to blacks through CDC-funded health departments (3). CDC supports a range of efforts to reduce the risk for acquiring or transmitting HIV infection among blacks (https://www.cdc.gov/features/ BlackHIVAIDSAwareness).

\section{References}

1. US Census Bureau. Population and housing unit estimates datasets 2017. Washington, DC: US Department of Commerce, US Census Bureau; 2016. https://www.census.gov/programs-surveys/ popest/data/data-sets.html

2. CDC. Diagnosis of HIV infection in the United States and dependent areas, 2017. HIV surveillance report, vol. 29. Atlanta, GA: US Department of Health and Human Services, CDC; 2018. https://www.cdc.gov/hiv/pdf/library/reports/surveillance/ cdc-hiv-surveillance-report-2017-vol-29.pdf

3. Rao S, Song W, Mulatu MS, Rorie M, O’Connor K, Scales L. HIV partner service delivery among blacks or African Americans — United States; 2016. MMWR Morb Mortal Wkly Rep 2019;68:81-86.

\section{HIV Partner Service Delivery Among Blacks or African Americans - United States, 2016}

\author{
Shubha Rao, $\mathrm{MPH}^{1}$; Wei Song, $\mathrm{PhD}^{1}$; Mesfin S. Mulatu $\mathrm{PhD}^{1}$; Michele \\ Rorie, $\mathrm{DrPH}^{1}$; Kevin O'Connor, $\mathrm{MA}^{1}$; Lamont Scales, $\mathrm{MA}^{2}$
}

Identifying persons with human immunodeficiency virus (HIV) infection who are unaware of their infection status, linking them to HIV care, and reducing racial/ethnic disparities are important national HIV prevention goals (1). Blacks/African Americans (blacks)* are disproportionately affected by HIV infection in the United States. Although blacks represent 13\% of the U.S. population (2), in 2017, 44\% of diagnoses of HIV infection were in blacks, and the rate of new diagnoses in blacks (41.1 per 100,000 persons) was approximately eight times that of non-Hispanic whites (5.1) (3). HIV partner services are offered by health officials to persons with diagnosed HIV infection (index patients) and their sex- or needle-sharing partners, who are notified of their potential HIV exposure and offered HIV testing and related services (4). CDC analyzed 2016

* Persons categorized as blacks/African Americans were not Hispanic or Latino.

\section{INSIDE}

87 Use of Toothpaste and Toothbrushing Patterns Among Children and Adolescents - United States, 2013-2016

91 Postlicensure Safety Surveillance of Recombinant Zoster Vaccine (Shingrix) — United States, October 2017-June 2018

95 Notes From The Field: Mumps Outbreak in a Recently Vaccinated Population - Kosrae, Federated States of Micronesia, August-December, 2017

97 QuickStats

Continuing Education examination available at https://www.cdc.gov/mmwr/cme/conted_info.html\#weekly.

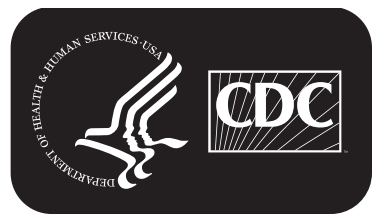


data from the National HIV Prevention Program Monitoring and Evaluation system submitted by 59 health departments. ${ }^{\dagger}$ Among 49,266 index patients identified as potential candidates for partner services, 21,191 (43\%) were black. The percentage of black index patients interviewed for partner services (76\%) was higher than that for all index patients combined (73\%). Among the 11,088 black partners named by index patients, $78 \%$ were notified of their potential HIV exposure. Fewer than half $(47 \%)$ of those notified were tested for HIV infection. Among those tested, one in six (17\%) received a new HIV diagnosis. The prevalence of newly diagnosed HIV infection was particularly high among black partners who were gay, bisexual, and other men who have sex with men (MSM) (37\%) and transgender persons (38\%). Effective implementation of partner services is important to identify HIV infection, link patients to care or reengage them in care, and provide prevention services to reduce HIV transmission.

In 2016, CDC funded 61 state and local health departments to implement comprehensive HIV prevention programs, including partner services. CDC analyzed HIV partner services client-level data in the National HIV Prevention Program Monitoring and Evaluation system submitted by 59 health

\footnotetext{
$\dagger^{\dagger}$ Fifty states, the District of Columbia, Puerto Rico, the U.S. Virgin Islands, and eight metropolitan statistical areas (MSAs) or specified metropolitan divisions (Baltimore, Chicago, Fulton County (Atlanta), Houston, Los Angeles County, New York City, Philadelphia, and San Francisco). In 2016, two health departments did not submit partner services data and were excluded from the analysis.
}

departments. Data were stratified by age group, gender, U.S. Census region, $\$$ HIV prevalence, $\mathbb{\$}$ and priority population (i.e., MSM, transgender persons, persons who inject drugs, heterosexual males, and heterosexual females). ${ }^{* *}$ An index patient is eligible for partner services if he or she is living within the jurisdiction at the time of report. Named partners are eligible for partner services if there is enough information to potentially locate and notify them of their exposure to HIV. Partners with newly diagnosed HIV infection are defined as

\footnotetext{
$\$$ U.S. Census regions (includes MSAs): Northeast: Connecticut, Maine, Massachusetts, New Hampshire, New Jersey, New York, New York City (New York), Pennsylvania, Philadelphia (Pennsylvania), and Rhode Island. Midwest: Chicago (Illinois), Indiana, Iowa, Kansas, Michigan, Minnesota, Missouri, Nebraska, North Dakota, Ohio, South Dakota, and Wisconsin; South: Alabama, Arkansas, Atlanta (Georgia), Baltimore (Maryland), Delaware, Florida, Georgia, Kentucky, Louisiana, Maryland, Mississippi, North Carolina, Oklahoma, South Carolina, Tennessee, Virginia, District of Columbia, and West Virginia. West: Alaska, Arizona, California, Colorado, Hawaii, Idaho, Los Angeles (California), Montana, Nevada, New Mexico, Oregon, San Francisco, Utah, Washington, and Wyoming; U.S. dependent areas: Puerto Rico and U.S. Virgin Islands.

HIV prevalence is defined based on the number of persons with diagnosed HIV infection in 2010. The jurisdictions are classified based on HIV prevalence as high: $\geq 20,000$; medium: 4,000-19,999; medium-low: 10003,999; low: <1,000. https://www.cdc.gov/hiv/pdf/policies/progressreports/ cdc-hiv-stateprogressreport.pdf.

** MSM includes males who reported male-to-male sexual contact and those who reported both male-to-male sexual contact and injection drug use in the past 12 months. Persons who inject drugs include persons who reported injection drug use in the past 12 months. Heterosexual males include males who only reported heterosexual contact with a female in the past 12 months. Heterosexual female includes females who only reported heterosexual contact with a male in the past 12 months.
}

The MMWR series of publications is published by the Center for Surveillance, Epidemiology, and Laboratory Services, Centers for Disease Control and Prevention (CDC), U.S. Department of Health and Human Services, Atlanta, GA 30329-4027.

Suggested citation: [Author names; first three, then et al., if more than six.] [Report title]. MMWR Morb Mortal Wkly Rep 2019;68:[inclusive page numbers].

\section{Centers for Disease Control and Prevention \\ Robert R. Redfield, MD, Director \\ Anne Schuchat, MD, Principal Deputy Director \\ Leslie Dauphin, PhD, Acting Associate Director for Science \\ Barbara Ellis, PhD, MS, Acting Director, Office of Science Quality \\ Chesley L. Richards, MD, MPH, Deputy Director for Public Health Scientific Services \\ Michael F. Iademarco, MD, MPH, Director, Center for Surveillance, Epidemiology, and Laboratory Services}

MMWR Editorial and Production Staff (Weekly)
Martha F. Boyd, Lead Visual Information Specialist Maureen A. Leahy, Julia C. Martinroe, Stephen R. Spriggs, Tong Yang, Visual Information Specialists

Quang M. Doan, MBA, Phyllis H. King, Terraye M. Starr, Moua Yang, Information Technology Specialists
MMWR Editorial Board Timothy F. Jones, MD, Chairman Robin Ikeda, MD, MPH Phyllis Meadows, PhD, MSN, RN Virgiton, MD, MPH Virginia A. Caine, MD Katherine Lyon Daniel, PhD Jonathan E. Fielding, MD, MPH, MBA David W. Fleming, MD William E. Halperin, MD, DrPH, MPH
Jewel Mullen, MD, MPH, MPA

Jeff Niederdeppe, PhD

Patricia Quinlisk, MD, MPH
Stephen C. Redd, MD

Patrick L. Remington, MD, MPH

Carlos Roig, MS, MA

William Schaffner, MD

Morgan Bobb Swanson, BS 
TABLE 1. Number and percentage of all index patients and black index patients offered services through human immunodeficiency virus (HIV) partner services, by demographic characteristics and priority populations - United States, ${ }^{*} 2016$

\begin{tabular}{|c|c|c|c|c|}
\hline \multirow[b]{2}{*}{ Characteristic } & \multicolumn{2}{|c|}{ All index patients } & \multicolumn{2}{|c|}{ Black index patients } \\
\hline & No. (\% of total) & No. (\%) interviewed & No. (\% of total index patients) & No. (\%) interviewed \\
\hline Total & $49,266(100.0)$ & $36,037(73.1)$ & $21,191(43.0)$ & $16,153(76.2)$ \\
\hline \multicolumn{5}{|l|}{ Age group (yrs) ${ }^{\dagger}$} \\
\hline $13-19$ & $1,002(2.0)$ & $800(79.8)$ & $654(65.3)$ & $527(80.6)$ \\
\hline $20-29$ & $15,577(31.6)$ & $12,086(77.6)$ & $8,167(52.4)$ & $6,460(79.1)$ \\
\hline $30-39$ & $12,941(26.3)$ & $9,462(73.1)$ & $5,223(40.4)$ & 3,962 (75.9) \\
\hline $40-49$ & $8,569(17.4)$ & $5,956(69.5)$ & $2,853(33.3)$ & $2,075(72.7)$ \\
\hline$\geq 50$ & $10,635(21.6)$ & $7,545(70.9)$ & $4,163(39.1)$ & $3,112(74.8)$ \\
\hline \multicolumn{5}{|l|}{ Gender $\S$} \\
\hline Male & $40,148(81.5)$ & $29,167(72.6)$ & $15,853(39.5)$ & $12,007(75.7)$ \\
\hline Female & $7,076(14.4)$ & $5,308(75.0)$ & 4,352 (61.5) & $3,323(76.4)$ \\
\hline \multicolumn{5}{|l|}{ U.S. Census region" } \\
\hline Northeast & $5,884(11.9)$ & $4,696(79.8)$ & $2,760(46.9)$ & $2,222(80.5)$ \\
\hline Midwest & $4,263(8.7)$ & $2,586(60.7)$ & $2,026(47.5)$ & $1,279(63.1)$ \\
\hline South & $28,002(56.8)$ & $22,387(79.9)$ & $14,516(51.8)$ & $11,538(79.5)$ \\
\hline West & $10,772(21.9)$ & $6,031(56.0)$ & $1,882(17.5)$ & $1,108(58.9)$ \\
\hline U.S. dependent areas & $345(0.7)$ & $337(97.7)$ & $7(2.0)$ & $6(85.7)$ \\
\hline \multicolumn{5}{|l|}{ HIV prevalence ${ }^{* *}$} \\
\hline High & $32,920(66.8)$ & $24,486(74.4)$ & $1,4084(42.8)$ & 11,207 (79.6) \\
\hline Medium & $14,876(30.2)$ & $10,466(70.4)$ & $6,763(45.5)$ & $4,685(69.3)$ \\
\hline Medium-low & $1,128(2.3)$ & $812(72.0)$ & $274(24.3)$ & 199 (72.6) \\
\hline Low & $342(0.7)$ & $273(79.8)$ & $70(20.5)$ & $62(88.6)$ \\
\hline \multicolumn{5}{|l|}{ Priority population ${ }^{\dagger \dagger}$} \\
\hline MSM & $22,780(46.2)$ & $19,200(84.3)$ & $8,155(35.8)$ & $7,362(90.3)$ \\
\hline Transgender persons & $507(1.0)$ & $374(73.8)$ & $284(56.0)$ & $226(79.6)$ \\
\hline Persons who inject drugs & 768 (1.6) & $640(83.3)$ & $192(25.0)$ & 166 (86.5) \\
\hline Heterosexual men & $4,125(8.4)$ & 3,705 (89.8) & 2,395 (58.1) & $2,192(91.5)$ \\
\hline Heterosexual women & $3,914(7.9)$ & $3,568(91.2)$ & $2,523(64.5)$ & $2,340(92.7)$ \\
\hline
\end{tabular}

Abbreviation: MSM = gay, bisexual, and other men who have sex with men.

* Includes U.S. dependent areas of Puerto Rico and the U.S. Virgin Islands.

' Because of missing/invalid data, records were excluded in the column "All index patients" for number of index patients (542; 1.1\%) and number interviewed $(188 ; 0.5 \%)$ and in the column "Black index patients" for number of black index patients $(131 ; 0.6 \%)$ and number interviewed $(17 ; 0.1 \%)$.

$\S$ Records for transgender persons and other missing/invalid genders were excluded in the column "All index patients" for number of index patients ( 2,$042 ; 4.1 \%)$ and number interviewed $(1,562 ; 4.3 \%)$ and in the column "Black Index Patients" for number of black index patients $(986 ; 4.7 \%)$ and number interviewed patients $(823 ; 5.1 \%)$

" Northeast: Connecticut, Maine, Massachusetts, New Hampshire, New Jersey, New York, Pennsylvania, Rhode Island, and Vermont; Midwest: Illinois, Indiana, lowa, Kansas, Michigan, Minnesota, Missouri, Nebraska, North Dakota, Ohio, South Dakota, and Wisconsin; South: Alabama, Arkansas, Delaware, District of Columbia, Florida, Georgia, Kentucky, Louisiana, Maryland, Mississippi, North Carolina, Oklahoma, South Carolina, Tennessee, Texas, Virginia, and West Virginia; West: Alaska, Arizona, California, Colorado, Hawaii, Idaho, Montana, Nevada, New Mexico, Oregon, Utah, Washington, and Wyoming; U.S. dependent areas: Puerto Rico and U.S. Virgin Islands. Two states did not submit data.

** Jurisdictions are grouped according to HIV prevalence and based on the number of persons with diagnosed HIV infection in 2010 (high: $\geq 20,000$; medium: 4,000-19,999; medium-low: 1,000-3,999; and low: $<1,000$ ).

${ }^{+\dagger}$ Because of missing risk information, records were excluded in the column "All index patients" for number of index patients $(17,172 ; 34.9 \%)$ and number interviewed $(8,550 ; 20.7 \%)$ and in the column "Black index patients" for number of black index patients $(7,642 ; 36.1 \%)$ and number interviewed $(3,867 ; 23.9 \%)$. MSM include males who reported male-to-male sexual contact as well as males who reported both male-to-male sexual contact and injection drug use in the past 12 months. Persons who inject drugs include persons who reported injection drug use in the past 12 months. Heterosexual males include males who only reported heterosexual contact with a female in the past 12 months. Heterosexual females include females who only reported heterosexual contact with a male in the past 12 months. Data on behavioral risk factors used to define the priority population were required for HIV-positive persons and optional for HIV-negative persons.

those who test positive for HIV through partner services-initiated HIV testing and have no evidence of a previous HIV diagnosis reported to the health department surveillance system; recorded in a laboratory report, medical record, or other available data source (e.g., partner services database or records of previous treatment for HIV infection); or recorded in a patient self-report. Partners with a previous diagnosis of HIV infection are those who test positive and have evidence of a previous HIV diagnosis. Data on index patients and partners were extracted from two databases that did not link the race/ethnicity of index patients and partners. Thus, black partners included in this analysis could have been named by index patients of any race/ethnicity. Data on behavioral risk factors used to define the priority population were required for HIV-positive persons and optional for HIV-negative persons. The key outcomes for this analysis include the percentage of black index patients who were interviewed for partner services, 
TABLE 2. Number and percentage of black partners named, notified, and tested, and new and previous diagnoses of human immunodeficiency virus (HIV) infection through HIV partner services programs, by characteristic — United States,* 2016

\begin{tabular}{|c|c|c|c|c|c|}
\hline Characteristic & $\begin{array}{l}\text { Named partners, } \\
\text { no. (\% by group) }\end{array}$ & $\begin{array}{c}\text { Named } \\
\text { partners notified, } \\
\text { no. }(\%)\end{array}$ & $\begin{array}{c}\text { Notified } \\
\text { partners tested, } \\
\text { no. }(\%)\end{array}$ & $\begin{array}{c}\text { Tested partners with } \\
\text { newly diagnosed } \\
\text { HIV infection, } \\
\text { no. (\%) }\end{array}$ & $\begin{array}{c}\text { Tested partners with } \\
\text { previously diagnosed } \\
\text { HIV infection, } \\
\text { no. (\%) }\end{array}$ \\
\hline Total & $11,088(100.0)$ & $8,616(77.7)$ & $4,080(47.4)$ & $690(16.9)$ & $361(8.8)$ \\
\hline \multicolumn{6}{|l|}{ Age groups (yrs) ${ }^{\dagger}$} \\
\hline $13-19$ & $248(2.2)$ & 194 (78.2) & $126(64.9)$ & 15 (11.9) & $7(5.6)$ \\
\hline $20-29$ & $4,136(37.3)$ & $3,260(78.8)$ & $1,837(56.3)$ & $275(15.0)$ & $183(10.0)$ \\
\hline $30-39$ & $2,484(22.4)$ & 1,909 (76.9) & $1,032(54.1)$ & $173(16.8)$ & $89(8.6)$ \\
\hline $40-49$ & $1,170(10.6)$ & $914(78.1)$ & $504(55.1)$ & $78(15.5)$ & $36(7.1)$ \\
\hline$\geq 50$ & $2,113(19.1)$ & $1,792(84.8)$ & $483(27.0)$ & $140(29.0)$ & $44(9.1)$ \\
\hline \multicolumn{6}{|l|}{ Gender $§$} \\
\hline Male & $8,563(77.2)$ & 6,555 (76.6) & $3,168(48.3)$ & $540(17.0)$ & $285(9.0)$ \\
\hline Female & $1,736(15.7)$ & $1,389(80.0)$ & $839(60.4)$ & $98(11.7)$ & $74(8.8)$ \\
\hline \multicolumn{6}{|l|}{ U.S. Census region? } \\
\hline Northeast & $1,406(12.7)$ & $704(50.1)$ & $355(50.4)$ & $72(20.3)$ & $8(2.3)$ \\
\hline Midwest & $1,130(10.2)$ & $650(57.5)$ & $273(42.0)$ & $64(23.4)$ & $7(2.6)$ \\
\hline South & $7,848(70.8)$ & $6,872(87.6)$ & $3,268(47.6)$ & $539(16.5)$ & $335(10.3)$ \\
\hline West & $700(6.3)$ & $388(55.4)$ & 183 (47.2) & $14(7.7)$ & $11(6.0)$ \\
\hline U.S. dependent areas & $4(0.0)$ & $2(50.0)$ & $1(50.0)$ & $1(100.0)$ & $0(-)$ \\
\hline \multicolumn{6}{|l|}{ HIV prevalence ${ }^{* *}$} \\
\hline High & 7,407 (66.8) & $6,353(85.8)$ & $2,964(46.7)$ & $376(12.7)$ & $270(9.1)$ \\
\hline Medium & $3,388(30.6)$ & $2,078(61.3)$ & $1,030(49.6)$ & $292(28.3)$ & 85 (8.3) \\
\hline Medium-low & $265(2.4)$ & $163(61.5)$ & $70(42.9)$ & $20(28.6)$ & $3(4.3)$ \\
\hline Low & $28(0.3)$ & $22(78.6)$ & $16(72.7)$ & $2(12.5)$ & $3(18.8)$ \\
\hline \multicolumn{6}{|l|}{ Priority population ${ }^{\dagger \dagger}$} \\
\hline MSM & 1,731 (15.6) & 1,392 (80.4) & $839(60.3)$ & 309 (36.8) & $170(20.3)$ \\
\hline Transgender persons & $58(0.5)$ & $40(69.0)$ & $16(40.0)$ & $6(37.5)$ & $1(6.3)$ \\
\hline Persons who inject drugs & $17(0.2)$ & $15(88.2)$ & $8(53.3)$ & $2(25.0)$ & $1(12.5)$ \\
\hline Heterosexual men & $542(4.9)$ & $452(83.4)$ & $309(68.4)$ & $69(22.3)$ & $66(21.4)$ \\
\hline Heterosexual women & $467(4.2)$ & $398(85.2)$ & $270(67.8)$ & $65(24.1)$ & $55(20.4)$ \\
\hline
\end{tabular}

Abbreviation: MSM = gay, bisexual, and other men who have sex with men.

* Includes U.S. dependent areas of Puerto Rico and the U.S. Virgin Islands.

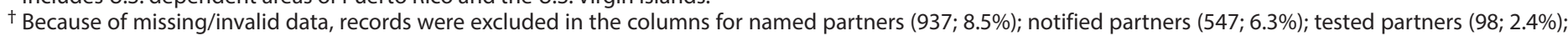
newly diagnosed HIV-positive partners (9; 1.3\%); and previously diagnosed HIV-positive partners $(2 ; 0.2 \%)$.

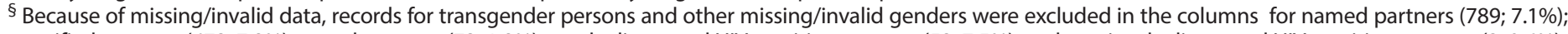

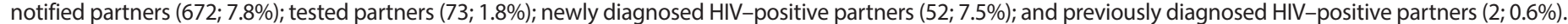

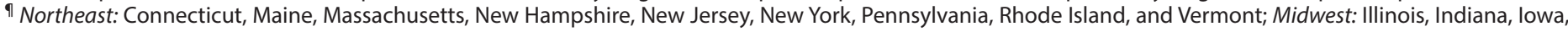

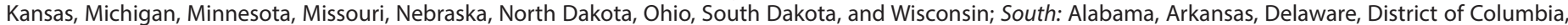

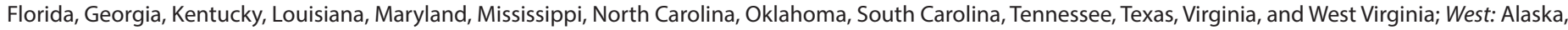

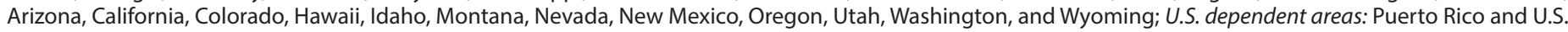
Virgin Islands. Two states did not submit data.

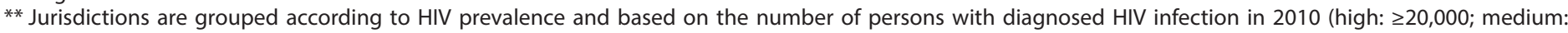
4,000-19,999; medium-low: 1,000-3,999; and low: <1,000).

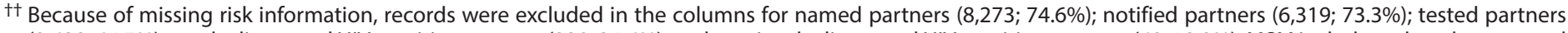

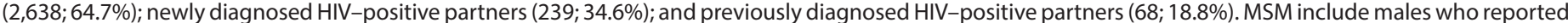

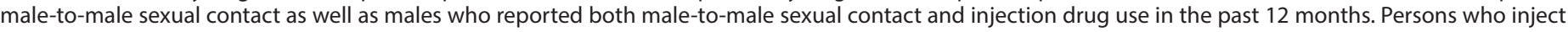

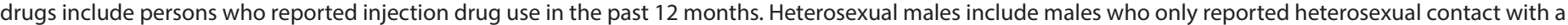

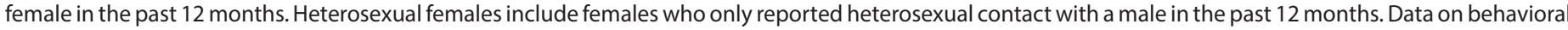
risk factors used to define the priority population were required for HIV-positive persons and optional for HIV-negative persons.

HIV status, and the HIV positivity rate among black partners named during the partner services interviews.

Overall, 49,266 index patients were identified as potential candidates for partner services in 2016, including 21,191 (43.0\%) who were black (Table 1 ). The percentage of interviews of black index patients by partner services were higher among those aged 13-19 years (80.6\%); females (76.4\%); persons residing in the Northeast $(80.5 \%)$ (excluding U.S. dependent areas); persons residing in low HIV prevalence areas $(88.6 \%)$, and heterosexual women $(92.7 \%)$. Among priority populations, percentages of interviews among black index patients by partner services exceeded $90 \%$ among heterosexual women $(92.7 \%)$, heterosexual men $(91.5 \%)$, and MSM (90.3\%); the lowest percentages of interviews among black index patients occurred among those who inject drugs (86.5\%) and transgender patients (79.6\%).

Among 27,779 partners named by index patients in 2016, a total of 11,088 (39.9\%) were black (Table 2). Among named partners who were black, $77.7 \%(8,616)$ were notified of their potential HIV exposure. Among partners who were 
notified, 4,080 (47.4\%) were tested for HIV infection. The highest percentages of testing occurred among black partners aged $13-19$ years $(64.9 \%)$; females $(60.4 \%)$; residents of the Northeast $(50.4 \%)$; residents of low HIV prevalence areas (72.7\%); and heterosexual men (68.4\%).

Among black partners tested in 2016, 16.9\% received a new diagnosis of HIV infection. Newly diagnosed HIV positivity among black partners was higher among persons aged $\geq 50$ years (29.0\%); males (17.0\%); those residing in the Midwest (23.4\%) (excluding U.S. dependent areas); persons residing in medium and medium-low prevalence areas $(28.3 \%$ and $28.6 \%$, respectively); transgender persons (37.5\%); and MSM (36.8\%). Among black partners tested, the percentage with previously diagnosed HIV infection was $8.8 \%$. The prevalence of previously diagnosed HIV infection among black partners tested was higher among persons aged 20-29 years (10.0\%); males (9.0\%); persons residing in the South $(10.3 \%)$; persons residing in low prevalence areas $(18.8 \%)$; and heterosexual men (21.4\%). Among black MSM partners, 60.3\% were tested for HIV.

\section{Discussion}

Among MSM, blacks accounted for 38\% of HIV diagnoses in 2017 (3). The present analysis found that partner services implemented by CDC-funded health departments interviewed approximately three of four black index patients. Index patients who were black MSM accounted for $45.6 \%$ (7,362 of $16,153)$ of partner services interviews among all black index patients, and approximately $90 \%$ of those in this group were interviewed. Fewer than half of all black partners notified of their potential HIV exposure were tested. Among those tested, one in six received a new diagnosis of HIV infection, and one in $11 \mathrm{had}$ a previous diagnosis. The rate of newly diagnosed HIV infection was particularly high among black partners who were MSM (37\%) and transgender persons (38\%). The high HIV positivity rates among black partners and black MSM partners who were tested are consistent with previous findings that indicate partner services is an effective, high-yield strategy for identifying undiagnosed HIV infections $(5,6)$. Prevention efforts that promote HIV testing and consistently include partner services might increase early diagnosis and improve HIV-related health outcomes among blacks, particularly among black MSM and transgender persons.

The findings in this report are subject to at least three limitations. First, although CDC provides recommendations outlining the basic elements of partner services (4), health department implementation varies considerably. Health departments employ different methods and models for partner services that depend on local legislation and regulations, local service delivery systems, and available resources, including

\section{Summary}

What is already known about this topic?

In 2017, the rate of diagnosis of new human immunodeficiency virus (HIV) infection among blacks/African Americans (blacks) was approximately eight times that of non-Hispanic whites.

What is added by this report?

In $2016,78 \%$ of black index patients were interviewed for partner services. However, among black partners, fewer than half were tested for HIV infection, $17 \%$ received a new diagnosis of HIV infection, and $9 \%$ were previously infected. The prevalence of newly diagnosed HIV infection was particularly high among black partners who were gay, bisexual, and other men who have sex with men (MSM) (37\%) and transgender persons (38\%).

What are the implications for public health practice?

Focusing effective implementation of partner services for blacks, especially for MSM and transgender persons, could lead to reductions in HIV incidence and HIV-related inequities.

trained disease intervention specialists. Second, the rate of newly diagnosed HIV infection might have been overestimated in those jurisdictions that do not routinely check their laboratory or surveillance records to identify persons with previously diagnosed HIV infection and those jurisdictions with a large proportion of missing data on behavioral risk information. Finally, even though partner services evaluation data requirements are standardized, data collection approaches and systems vary among CDC-funded recipients.

Full and effective implementation of partner services programs to reach all index patients and partners, particularly black MSM and transgender persons, as recommended by the National HIV/ Acquired Immunodeficiency Syndrome (AIDS) Strategy, is important to identifying persons who are unaware of their HIV status (1). Further, partner services program managers need to ensure that disease intervention specialists have access to all the resources needed to identify and locate partners named by index patients during partner services interviews and to link newly diagnosed partners to HIV medical care. In addition, partner services offer the opportunity to reengage both index patients and previously diagnosed partners who are not in care (4). Partner services can also facilitate linkage to HIV preexposure prophylaxis and other prevention services, especially for high risk HIV-negative partners of HIV-positive persons, to reduce their risk of HIV acquisition ( 7 ). Barriers to effective implementation of partner services and HIV testing include client concerns about compromised confidentiality and fear of negative impacts (e.g., abuse, stigmatization, medical mistrust, and abandonment) (8-10). Therefore, HIV prevention programs, such as partner services that focus on increasing testing, enhancing linkage to HIV care, reengaging patients with previously diagnosed HIV 
infection in care, providing prophylactic treatment, and increasing access to support services for blacks, would help to address barriers to service and so reduce onward HIV transmission and HIV-related health disparities.

\section{Acknowledgments}

Hui Zhang, Lisa Kimbrough, Janet Heitgerd, Program Evaluation Branch, Division of HIV/AIDS Prevention, National Center for HIV/ AIDS, Viral Hepatitis, STD, and TB Prevention, CDC; Prevention Program Branch, Quantitative Sciences and Data Management Branch, Division of HIV AIDS Prevention, National Center for HIV/AIDS, Viral Hepatitis, STD, and TB Prevention, CDC.

Corresponding author: Shubha Rao, SRao1@cdc.gov, 404-639-8521.

${ }^{1}$ Division of HIV/AIDS Prevention, National Center for HIV/AIDS, Viral Hepatitis, STD, and TB Prevention, CDC; ${ }^{2}$ Office of Health Equity, Division of HIV/AIDS Prevention, National Center for HIV/AIDS, Viral Hepatitis, STD, and TB Prevention, CDC.

All authors have completed and submitted the ICMJE form for disclosure of potential conflicts of interest. No potential conflicts of interest were disclosed.

\section{References}

1. Office of National AIDS Policy. National HIV/AIDS strategy for the United States: updated to 2020. Washington, DC: The White House, Office of National AIDS Policy; 2015. https://files.hiv.gov/s3fs-public/ nhas-update.pdf

2. US Census Bureau. Population and housing unit estimates datasets. Suitland, MD: U.S. Department of Commerce; US Census Bureau; 2018. https://www.census.gov/programs-surveys/popest/data/data-sets.html
3. CDC. Diagnoses of HIV infection in the United States and dependent areas, 2017. HIV surveillance report, vol. 29. Atlanta, GA: US Department of Health and Human Services, CDC; 2018. https://www. cdc.gov/hiv/pdf/library/reports/surveillance/cdc-hiv-surveillance-report2017-vol-29.pdf

4. CDC. Recommendations for partner services programs for HIV infection, syphilis, gonorrhea, and chlamydial infection. Atlanta, GA: US Department of Health and Human Services, CDC; 2008. https:// www.cdc.gov/mmwr/preview/mmwrhtml/rr57e1030a1.htm

5. Hogben M, McNally T, McPheeters M, Hutchinson AB. The effectiveness of HIV partner counseling and referral services in increasing identification of HIV-positive individuals a systematic review. Am J Prev Med 2007;33(Suppl):S89-100. https://doi.org/10.1016/j. amepre.2007.04.015

6. Varghese B, Peterman TA, Holtgrave DR. Cost-effectiveness of counseling and testing and partner notification: a decision analysis. AIDS 1999;13:1745-51. https://doi.org/10.1097/00002030-199909100-00019

7. Song W, Mulatu MS, Rorie M, Zhang H, Gilford JW. HIV testing and positivity patterns of partners of HIV-diagnosed people in partner services programs, United States, 2013-2014. Public Health Rep 2017;132:455-62. https://doi.org/10.1177/0033354917710943

8. Passin WF, Kim AS, Hutchinson AB, Crepaz N, Herbst JH, Lyles CM; HIV/AIDS Prevention Research Synthesis Project Team. A systematic review of HIV partner counseling and referral services: client and provider attitudes, preferences, practices, and experiences. Sex Transm Dis 2006;33:320-8. https://doi.org/10.1097/01.olq.0000194597.16236.48

9. Eaton LA, Driffin DD, Kegler C, et al. The role of stigma and medical mistrust in the routine health care engagement of black men who have sex with men. Am J Public Health 2015;105:e75-82. https://doi. org/10.2105/AJPH.2014.302322

10. Levy ME, Wilton L, Phillips G 2nd, et al. Understanding structural barriers to accessing HIV testing and prevention services among black men who have sex with men (BMSM) in the United States. AIDS Behav 2014;18:972-96. https://doi.org/10.1007/s10461-014-0719-x 